\title{
Thermo and Mechanical Properties of Fine Silicon Carbide /Chopped Carbon Fiber Reinforced Epoxy Composites
}

\author{
Amal Nassar ${ }^{*}$ Eman Nassar \\ Department of Mechanical Engineering, Higher Technological Institute, Tenth of Ramadan City, Egypt \\ *Corresponding Author: Amal.nasser@hti.edu.eg
}

Copyright (C) 2014 Horizon Research Publishing All rights reserved.

\begin{abstract}
The effect of addition of fine size from $\mathrm{SiC}$ material $(\mathrm{SiC})$ with different weight percentage on the mechanical; thermal and physical properties of chopped carbon fiber reinforced epoxy composite has been studied. Mechanical and physical properties are studied by the change in the $\mathrm{SiC}$ material content to study the behavior of the composite material when it is subjected to load. The thermo mechanical properties are studied by using dynamic mechanical analyzer. The results for mechanical and physical properties of fine $\mathrm{SiC}$ material $(\mathrm{SiC})$ filled carbon fiber reinforced epoxy composite are improved than unfilled carbon fiber reinforced epoxy composite. Analysis of viscoelastic for the different $\mathrm{SiC}$ content indicate adding 25 wt. \% from $\mathrm{SiC}$ reducing the capacity of the energy absorption of the composite material and increasing the elastic behavior of the composite.
\end{abstract}

Keywords Mechanical, Physical, Thermal, SiC, Epoxy Composite, Chopped Carbon Fiber

\section{Introduction}

Epoxy is a type of strong adhesive used to stick things together and to cover surfaces. Epoxy has been used widely in the industrial application and in the aerospace field [1]. There are many methods to improve the properties of epoxy by adding particles in the resin such as the liquid rubbers, the copolymers, the silica nanoparticles, the thermoplastics, the core shell particles ,the silicate layers, , and the combinations of these [2]. Mechanical properties for epoxy composite material determine by the life it can be expected to service. Determine the mechanical properties of epoxy composite occupy considerable interest among researchers. Kochetov et al. [3] study the behavior of composite by preparing Nano composites filled with 3 types from ceramic materials $\left(\mathrm{SiO}_{2}\right.$, $\mathrm{Al}_{2} \mathrm{O}_{3}$, and $\mathrm{AIN}$ ) with different average particles size. They noticed the highest DC breakdown strength for 0.5 weight percent for two component system. It was also observed while the DC breakdown strength increased with 10 weight percent as compared to 2 and 5 weight percent and again decreased with 15 weight percent Nano-fillers. Daniel et al. [4] prepared epoxy composites and studied the effect of dispersion of clay nanoparticles in epoxy based composites by using a three roll mills with the concentration of 1 to 10 weight percent. They found the elastic modulus was improved up to $80 \%$ with 10 weight percent addition of clay Nano particles in the epoxy. They also observed no improvement in the tensile strength of the Nano composites over pure epoxy; this was due to nanoparticles clustering and/or to the occasional occurrence of Nano to micro size voids in the microstructure. J. Gao et al. [5] prepared the Nano Epoxy composites with added Nano clay and a novel ultrafine full vulcanized rubber powder. The property of the (epoxy / rubber / clay Nano composite) has been studied by using X-ray diffraction and by using transmission electron microscopy. They observe the unmodified clay was fully exfoliated and uniformly dispersed in the Nano composites resulting and found they also noticed the impact strength of this special epoxy / rubber / clay Nano composite) increased up $107 \%$ over the neat epoxy resin. Iovu et al. [6] they prepare epoxy based Nano composites s reinforced with multi walled carbon Nano tubes. They noticed the structure of amine multi walled carbon Nano tubes B 100 exhibit compatibility with the epoxy matrix. Frache et al. [7] they prepare epoxy based Nano composites reinforced with homemade hydrotalcites and mon-tmorillonite type layered silicates and studied the properties Their research revealed possibility to get Nano structured materials, characterized by resin intercalation into hydrotalcites galleries, by using suitable exchange for the pristine (HTlc) with stearate anions. The results of the thermal analysis showed Nano composites $\mathrm{s}$ based on hydrotalcites were prone to decompose, both in nitrogen and in air. Jasiuk et al. [8] study the behavior of polyurethane matrix reinforced with micron and Nano sized silica inclusions. They studied the density of composite further can be enhanced with micron sized inclusions as compared to density of Nano-sized inclusions. Cheung et al. [9] prepared Nano composites with a poly propylene matrix 
and a calcium carbonate by melting mixing of the components. Many researchers have also used a form of melt the mixing to produce Nano composites [10].Wang et al. [11] prepared a novel kind from carbon foam and reinforced carbon-carbon composite, they found the compressive strength increased by $38.9 \%, 66.7 \%$ and $29.4 \%$ when the amount additive from chopped fibers was 1, 3 and 5 wt. \% respectively. Chitsazzadeh et al. [12] studied the influence of adding multi walled carbon nano-tubes on mechanical properties of chopped strand mat/polyester composites, They observed adding only 0.05 weight percent carbon nano-tube enhanced the flexural strength for the hybrid composite up to $45 \%$ while the tensile strength was not changed significantly. Sohn et al. [13] improved the delamination resistance of carbon epoxy composite laminates by adding Chopped Kevlar of S-7 mm in length and $18 \mathrm{~g} \mathrm{mp}^{2}$ in weight to area ratio. They noticed the compressive strengths of composite laminates are reduced when the Kevlar's number fiber layers is increased. The literature mentioned perversely gives a short overview about the effects of addition of fibers; particles or both to mechanical and thermal properties of the epoxy composites. It has been observed mechanical properties at optimum fiber loading conditions can be determined with the addition of fibers; particles or both as reinforcement on matrix composites.

\section{Materials}

Chopped carbon fiber with 3 to $8 \mathrm{~mm}$ long and $1.82 \mathrm{~g} / \mathrm{cm}^{3}$ density supplied by Jiangsu company in China, is used as a fiber reinforcement. The $\mathrm{SiC}$ was received in the form of powder from SABI Company in Egypt with size equal 35 to $65 \mu \mathrm{m}$. It was washed with water to remove any impurity particles. Ball mill is used to grind silicon carbide particles to fine size. Figure 1 shows the ball mill used in this study, silicon carbide particles were grinded for $120 \mathrm{hr}$. to reach to average size equals $5 \mu \mathrm{m}$. Epoxy (EPOBOND Epoxy) supplied from epobond for chemicals and electrical components in Egypt have Viscosity equal $2475 \mathrm{mPa} \cdot \mathrm{s}$ at $25^{\circ} \mathrm{C}$

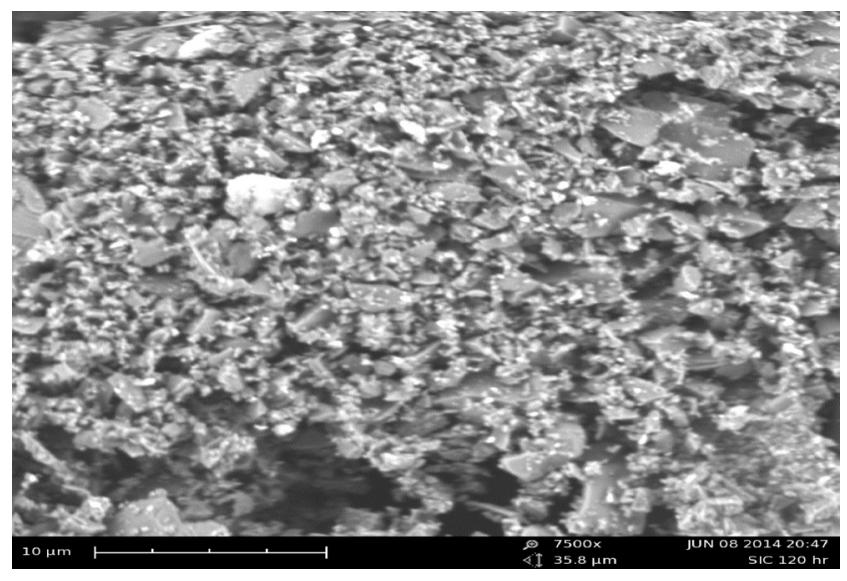

Figure 1. SEM for silicon carbide particles after grinded to $120 \mathrm{hr}$. in ball mill
The composites were fabricated by blending epoxy resin, carbon fiber, and Fine $\mathrm{SiC}$ in a certain weight percentage. Four different compositions of composites were prepared by varying the Fine $\mathrm{SiC}$ reinforcement with fixed weight percentage from chopped carbon fiber reinforcement. Fine $\mathrm{SiC}$ in five different weight percentages $(0,10,15$, and 25 weight percentage) are added with fixed $15 \mathrm{wt} . \%$ of chopped carbon fiber and remaining epoxy so as noticing fine's effect on the physical; thermal and mechanical properties for the epoxy composites. The average particle radius of spherical $\mathrm{SiC}$ fine particles was $5 \mu \mathrm{m}$. The composites were prepared by blending the certain wt. \% from carbon fiber, $\mathrm{SiC}$ fine particles and epoxy resin in containers and then poured in a mold have the desired dimensions then the composites a left for solidification at room temperature for $48 \mathrm{~h}$ then removed from the mold and marking is done according to American Society for Testing Materials (ASTM) test standards.

\section{Tests for Mechanical Properties}

The mechanical properties were studied to identify the behavior of the material at different loading conditions. To study how the materials break or deform as a function with the applied load; temperature and time, impact strength, tensile strength, flexural strength, wear rate and hardness of the composite specimens were determined. Vickers hardness (HV-10B Low Load Vickers Hardness Tester) is used to measure the hardness of the composite samples. Pyramid indenter was forced into the sample surface of the composite material under conditions of controlled magnitude and loading. Tensile test and flexural and shear strength and are done on a Computer- control polymer universal testing machine/universal testing machine (C-CPUTM). The tensile test is performed to determine the ductility of the composite material. Opposite and equal loads are applied at both ends of the sample on the C-CPUTM. The sample dimensions are $11.5 \mathrm{~mm}$ wide, $200 \mathrm{~mm}$ long and with different thickness according to the composite material composition. The flexural strength defines as the ability of the material to resist bending under load. Three points bend test was performed on the universal testing machine C-CPUTM with a span length equal $30 \mathrm{~mm}$ and between the supports and a crosshead speed of $10 \mathrm{~mm}$ per min to measure the amount of failure when subjected to load. The sample dimensions are $12.7 \mathrm{~mm}$ width, $6.35 \mathrm{~mm}$ thickness and $157 \mathrm{~mm}$ length.

The shear strength test is conducted as per ASTM D 2344-84 standards test on C-CPUTM with crosshead speed of $10 \mathrm{~mm}$ per min and span length of $50 \mathrm{~mm}$ is maintained for testing. Impact test is done to determine the capacity of energy consumption of the composite material before fracture. Charpy (V-notch) impact test samples have dimensions equal $(3.2 \times 64 \times 12.7) \mathrm{mm}$ and with $2.5 \mathrm{~mm}$ depth of $\mathrm{V}$ notch groove in the middle of the sample. The samples were fixed on the Charpy impact tester such notch was in opposite face to the striking end of the tester hammer. 


\section{Results and discussion}

The mechanical and physical properties describe the material behavior at various practical applications. Hardness test describe the physical properties. Measuring the behavior of the composite material under different load conditions is used to identify the mechanical properties. Tests were done to study the effect of addition of fine $\mathrm{SiC}$ particles on physical, thermal and mechanical properties. Hardness is a property for surface and is a wear resistance measure for the surface of the epoxy composite. The values for the hardness of all the four wt. \% of fine $\mathrm{SiC}$ are illustrated in Figure 2. It can be Seen from the Figure the hardness increases with the increase in the wt.\% from the fine $\mathrm{SiC}$ content . Hardness linearly increases from $0 \mathrm{wt} . \% \mathrm{SiC}$ to $15 \mathrm{wt} . \% \mathrm{SiC}$ content, but further increase in wt.\% of $\mathrm{SiC}$ content results in the decrease in the hardness value. This increasing in hardness value are attributed to the fact when the composition density increases by the reinforcement particles introduced between the matrix and the fiber, hardness increases and value of the specimen compression decreases. Same observation was found in our pervious study [1]. Addition of a small weight percentage of Nano $\mathrm{SiC}$ particles can significantly improve the wear resistance of the composites. The SiC Nano particles fill in the gap between the matrix and the fiber and made a dense structure and enhanced the composite hardness.

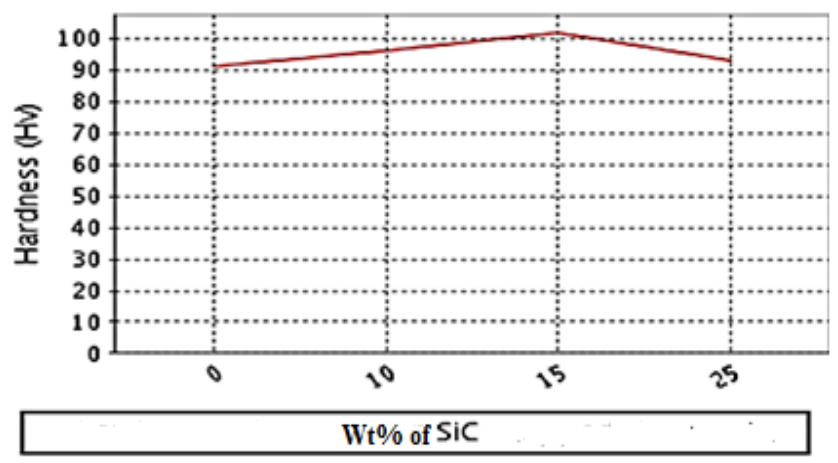

Figure 2. hardness of $\mathrm{SiC}$ chopped carbon fiber reinforced epoxy composites.

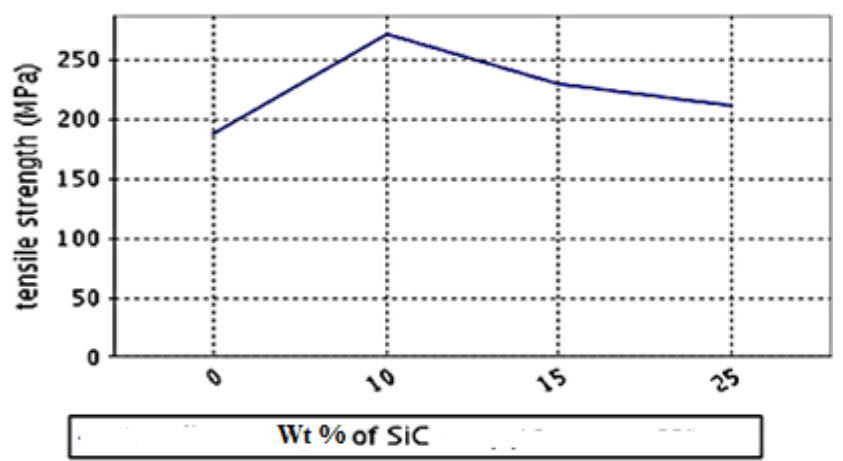

Figure 3. tensile strength for the epoxy composite reinforced with different wt. \% from $\mathrm{SiC}$ fine particles

The ultimate tensile strength is the maximum stress a material can withstand while being pulled or stretched before breaking, the value of the ultimate tensile strength calculated by dividing the maximum load for the material by the initial cross section of the test sample. Figure 3 shows the graph of the tensile strength in the different weight. \% of $\mathrm{SiC}$ fine particles. It can be Seen from the figure the tensile strength increases from 0 to 10 weigh percentage of the fine $\mathrm{SiC}$ content while the increases in the $\mathrm{SiC}$ content results in the decrease in the tensile strength value. This is because the fine particles act as an obstruction in the stress, transferring from point to another increasing the content from the fine $\mathrm{SiC} 10$ weight percent results in the increase of stress transfer from point to another. For the insufficient bonding between the three different, the loads cannot transfer from one end to another and hence the composite tensile strength was reduced. Tensile strength of the carbon fiber reinforced poly ether amide improves significantly with the increasing in the percentage of fiber reinforcement. The amount of the improvement in tensile strength, not proportional to the amount of the carbon fiber reinforcement $[14,15]$.

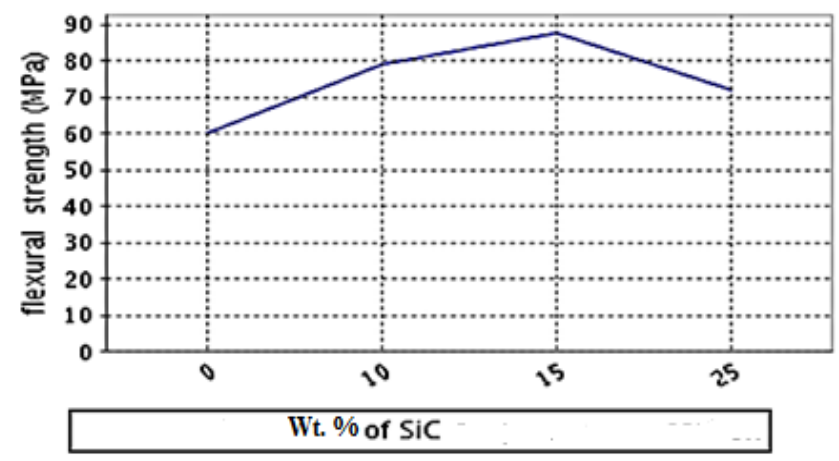

Figure 4. flexural strength for the epoxy composite reinforced with different wt. $\%$ from $\mathrm{SiC}$ fine particles

Figure 4 shows the flexural strength of the epoxy composite reinforced with different wt. \% from $\mathrm{SiC}$ fine particles. It can be seen from the figure the flexural strength increases from 60 to $79 \mathrm{MPa}$ with the increase in the content of the fine $\mathrm{SiC}$ particles from 0 to 10 wt. $\%$, when the content of the fine $\mathrm{SiC}$ particles more than $10 \mathrm{wt} . \%$, then the value of the flexural strength is decreased. When the sample is placed between two points of support and load is applied from the top of the sample, then the top layer of the sample is subjected to compressive loading; the sample body is subjected to bending whereas the bottom layer of the sample is subjected to tensile loading. If the bonding between the fiber/ reinforcement and matrix is increased, the flexural strength increases and the strong bonding help in transfer loads from one end of another leading to the increase in flexural strength of the sample, however when the percentage of fiber/ reinforcement goes beyond the required percentage, then surface area increases. Whereas the percentage of the matrix decreases; thus, strength of the bonding will be reduced and the loads cannot be transferred effectively from one part to another, which decrease the 
composite flexural strength. Another reason for this reduction in flexural strength, is with the addition of fine $\mathrm{SiC}$ particles more than 10 wt.\% the matrix disturbs the continuity and the bonding strength between reinforcement and matrix will reduce[16].

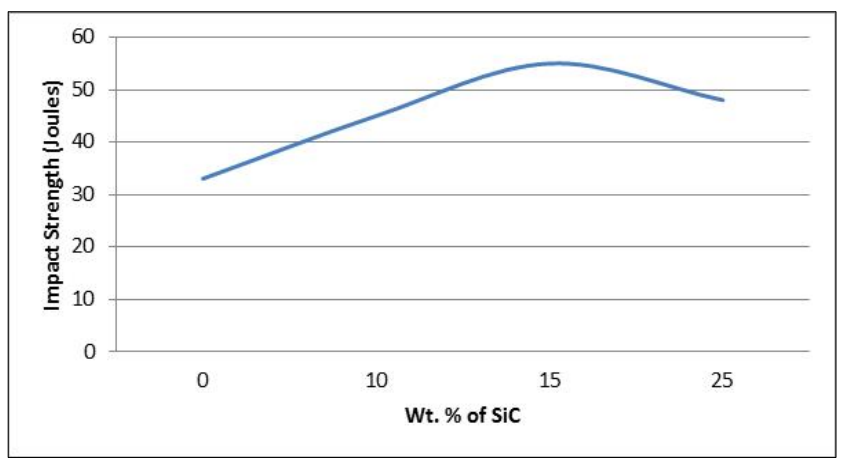

Figure 5. impact strength for the epoxy composite reinforced with different wt. \% from $\mathrm{SiC}$ fine particles

Toughness is the resistance of material's to fracture. The ductile material will absorb a considerable amount of energy before fracture, whereas the brittle material absorbs very little energy. Figure 5 shows the increasing in the value for the impact strength with the increases in the percentage of the reinforcement. The impact strength value increases from 0 to 15 wt. $\%$ and then decrease at $25 \mathrm{wt} \%$ from fine $\mathrm{SiC}$. This increasing in impact strength is may be due to the weaker bond, as the bond strength between the carbon fiber, fine $\mathrm{SiC}$ particles, and the epoxy reduces the capacity of the impact energy absorbing for the composite increases. The large amount of energy is absorbed by crack initiated along the filler, fiber and matrix interface during deboning. The capability of the energy absorbing by the composites depends on the constituent properties.

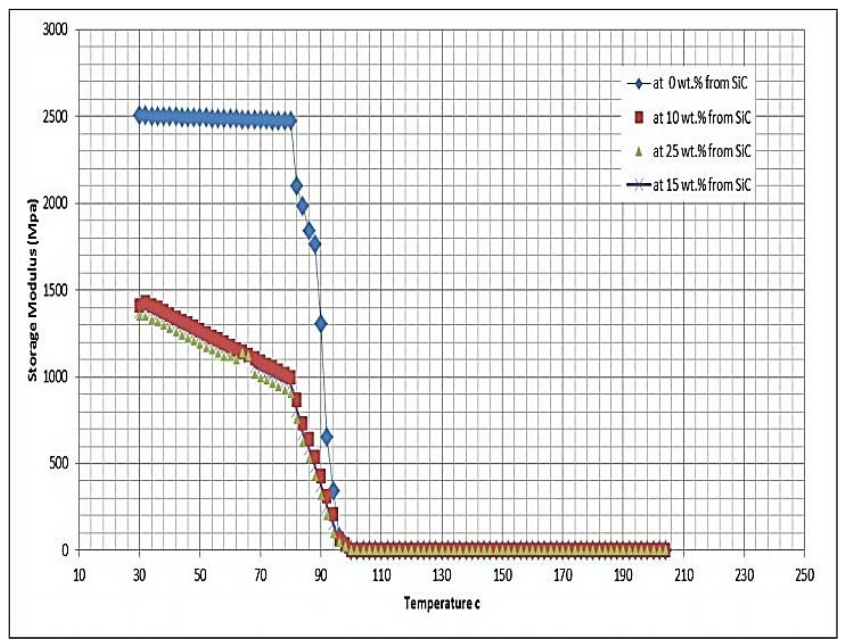

Figure 6. storage modulus for the epoxy composites at different temperatures.

Dynamic mechanical analysis is the most powerful tools available to study the behavior of the material. It measures the viscoelastic properties of the materials and it shows the materials properties; are very stable with temperature or there will be rapid changes which would render the material useless [17]. One of the important applications for the Dynamic mechanical analysis is a measurement for the temperature of the glass transition in polymers. the amorphous polymers have different temperatures for glass transition, above this temperature the material will have rubber properties instead of the glassy behavior so, the material stiffness will drop Significantly with an increase in viscosity[18]. Dynamic mechanical analysis of $\mathrm{SiC}$ reinforced chopped carbon fiber epoxy composite have been carried out in this paper to investigate the variation for the storage modulus. All tests made according to the ASTM D 4065-94 test standards at a fixed frequency of the oscillation of $1 \mathrm{~Hz}$ and the sample heating rate is $2{ }^{\circ} \mathrm{C} / \mathrm{min}$.

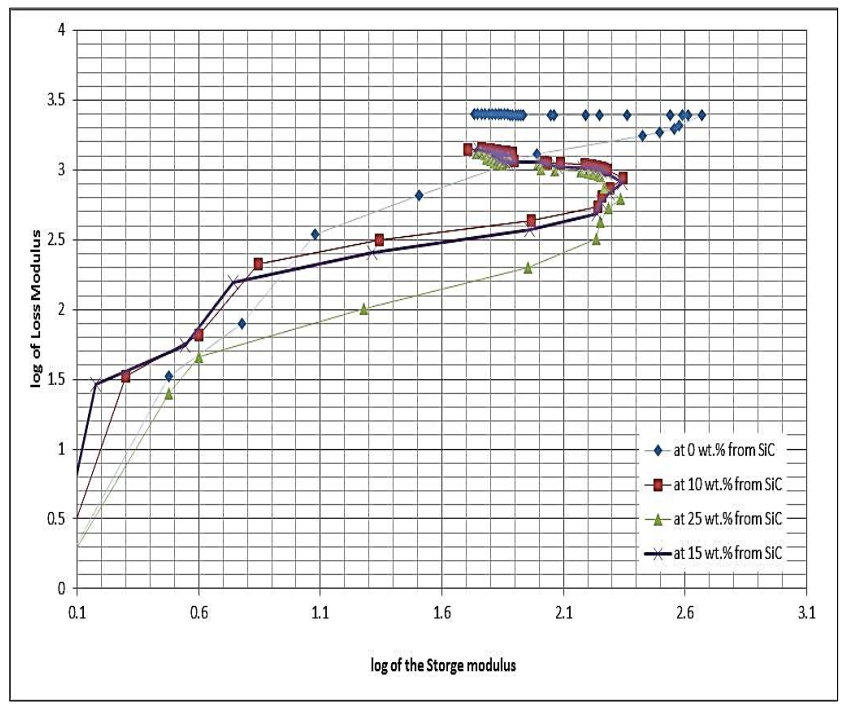

Figure 7. loss modulus for the epoxy composites at different temperatures

All tests were begun from the room temperature and goes to $205{ }^{\circ} \mathrm{C}$ temperature. Figures 6 and 7 show the storage modulus and the loss modulus (viscous), as a function of temperature. Figure 6 shows the graph of storage modulus versus the temperature for $\mathrm{SiC}$ fine particles- chopped carbon fiber-reinforced the epoxy composite. Figure 6 shows the epoxy composites trend a linear Behavior with a slight decrease in the storage modulus value with the change in the temperature (room temperature to $80^{\circ} \mathrm{C}$ ). So, we can say the glassy regime from room temperature to $78^{\circ} \mathrm{C}$ then sharp decline in the storage modulus values with the increase in the values of the temperature from $78{ }^{\circ} \mathrm{C}$ to $94{ }^{\circ} \mathrm{C}$. The composite changes from glassy to rubbery transition at the temperature range of $78{ }^{\circ} \mathrm{C}$ to $94{ }^{\circ} \mathrm{C}$; this is due to the sharp drop in the storage modulus value, , the material have lost its usefulness as a structural material. Due to the amorphous structure of polymer and the presence of the unorganized structure, the value of storage modulus drops suddenly. From $94{ }^{\circ} \mathrm{C}$ to $205^{\circ} \mathrm{C}$, the storage modulus values nearly tend to zero, which shows a rubber behavior indicating degradation of the moduli above $94{ }^{\circ} \mathrm{C}$. Figure 8 clearly shows the loss modulus value with the increase in value of the temperature. 
We notice from the figure the loss modulus values rise to a maximum as the values of the storage modulus are at their fastest rate of decent. Peak of the loss modulus curve indicates to the glass transition temperature. Figure 7 indicates the glass transition temperature as $95 \mathrm{C}$ and the desired minimum values for the loss modulus obtained at 10 to 25 wt. \% from fine $\mathrm{SiC}$ content. This may be due to increasing in the percentage of fiber and reinforcement content, i.e., as the percentage of fiber/ reinforcement content increases, the height of the curve decreases and the peak of width spread across the wide temperature range leading to decrease in the loss modulus value .Further, it has also been observed from the figure the composition with lower fiber/reinforcement content peak of the glass transition temperature shifted to lower temperature with the sharp peak and higher modulus value for the loss modulus.

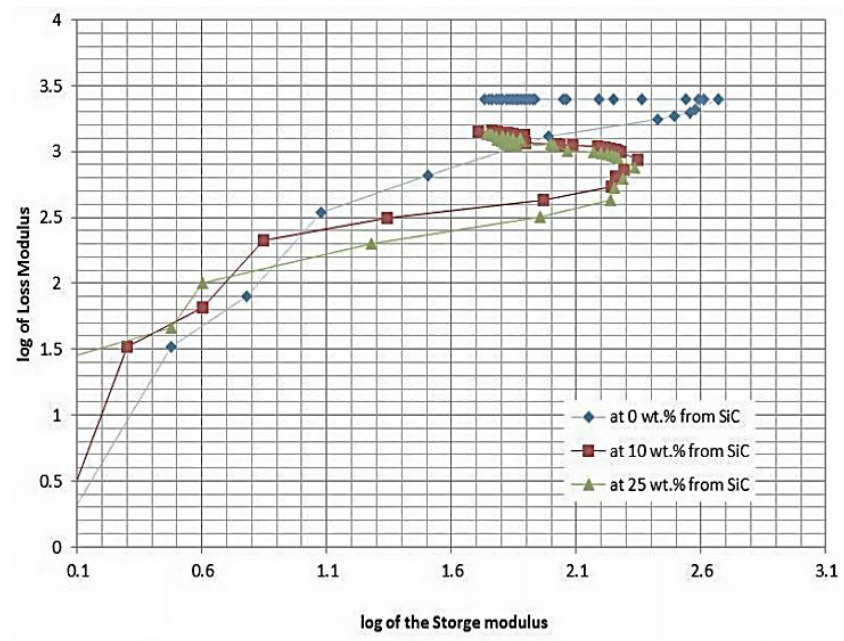

Figure 8. Cole-Cole plots for the epoxy composites.

Figure 8 shows the analysis carried on the epoxy composites by using the Cole-Cole analysis. Cole-Cole plot is used to predict the composite nature, whether it is heterogeneous or homogeneous [19]. A Cole-Cole is plotted for the storage modulus and the loss modulus, where the values of loss modulus are plotted on the $\mathrm{x}$ axis and the storage modulus values are plotted on the $y$ axis. The Cole-Cole plot is used for describing the analysis of molecular architecture. Changes in the architecture molecules of the sample model were readily detected as variations systematic in the shape and the displacements on Cole-Cole plot. The homogeneous system exhibits a semicircular curve, whereas the heterogeneous system exhibits an imperfect semicircle, also the matter of the curvature obtained in the Cole-Cole curve determines the adhesion between matrix and fiber. Investigated values of the epoxy composites show imperfect semicircles refers to heterogeneous nature. Also, unfilled carbon fiber reinforced epoxy composites show some homogeneous nature with respect to fine $\mathrm{SiC}$ filled carbon fiber reinforced the epoxy composites. This is may be due to adding fine $\mathrm{SiC}$ particle breaks the matrix continuity and then the nature is shifted to more heterogeneous tendency.

\section{Conclusions}

1. Mechanical properties increase with the increase in $\mathrm{SiC}$ fine particle filler content up to $10 \mathrm{wt}$. \% whereas the addition of $\mathrm{SiC}$ fine particle content more than 10 wt. \% results in the decrease in mechanical property.

2. The value of impact strength and hardness increases up to $15 \mathrm{wt} . \%$ of $\mathrm{SiC}$ fine particle content; whereas the value of flexural and tensile strength increases up to 10 wt $\%$ from $\mathrm{SiC}$ fine particle.

3. Values for the Storage modulus for the epoxy composite decreases with the increase in $\mathrm{SiC}$ fine particle content. Values of the Storage modulus decrease with the increase in the percentage of $\mathrm{SiC}$ fine particles content, whereas elastic range of the material increases with the increase in $\mathrm{SiC}$ fine particles content.

4. Epoxy composites show a heterogeneous nature. Also, unfilled carbon fiber reinforced epoxy composites exhibit homogeneous nature heterogeneous nature is due to the uneven distribution of the fine particles in the matrix.

5. The analysis of the mechanical and thermal properties, show the optimum properties for epoxy composite are obtained for $15 \mathrm{wt} . \%$ from fine $\mathrm{SiC}$ content in addition to 25 wt.\% chopped carbon fiber-reinforced epoxy composite.

\section{REFERENCES}

[1] Amal Nassar and Eman Nassar "Study on Mechanical Properties of Epoxy Polymer Reinforced with NanoSiC particles" . Nanoscience and Nanoengineering 1(2), (2013) 89-93.

[2] M .Jun, M. S. Mo, X .S. Du, S. R. Dai, and I. Luck,“ Study of epoxy toughened by in situ formed rubber nanoparticles," Journal ofApplied Polymer Science , 110(1) : (2008) 304312 .

[3] T. Andritsch, R. Kochetov, Y. T. Gebrekiros, U. Lafont, P. H. F. Morshuis, and J. J. Smit, "Synthesis and dielectric properties of epoxy based Nano composites s," in Proceedings of the Annual Report Conference on Electrical Insulation and Dielectric Phenomena (CEIDP '09), (2009) 523-526,.

[4] A. Yasmin, J. L. Abot, and I. M. Daniel, "Processing of clay/ epoxy Nano composites s by shear mixing," ScriptaMaterialia, vol. 49, no. 1,(2003)81-86.

[5] B. Li, X. Zhang, J. Gao , "Epoxy based Nano composites s with fully exfoliated unmodited clay: mechanical and thermal properties," Journal of Nanoscience and Nanotechnology, vol. 10,no. 9, (2010)5864-5868

[6] C. M. Damian, A. M. Pandele, C. Andronescu, A. Ghebaur, 
S. A. Garea, and H. Iovu, "Epoxy-based Nano composites s rein- forced with new amino functionalized multi-walled carbonnanotubes," Fullerenes Nanotubes and Carbon Nanostructures, vol. 19, no. 3 , (2011) 197-209

[7] A. Frache, O. Monticelli, M. Nocchetti, G. Tartaglione, and U. Costantino, "thermal properties of epoxy resin Nano composites s based on hydrotalcites," Polymer Degradation and Stability, vol. 96, no. 1, pp. 164-169, 2011.

[8] J. Jordan, K. I. Jacob, R. Tannenbaum, M. A. Sharaf, and I. Jasiuk, "Experimental trends in polymer Nano composites s-a review," Materials Science and Engineering A, vol. 393, no. 1-2 (2005)1-11,

[9] C.-M. Chan, J. Wu, J.-X. Li, Y.-K. Cheung," Polypropylene/calcium carbonate Nano composites", Polymer 43, (2002 ) 2981-2992,

[10] C.I. Park, O.O. Park, J.G. Lim, H.J. Kim, The Fabrication of Syndiotactic Polystyrene/organophilic Clay Nanocomposite and Their Properties, Polymer, Vol.42, No.17, (200 ) $7465-7475$.

[11] Xia Wang, Ruiying Luo , Yongfeng Ni, Renqin Zhang, Shaobo Wang" Properties of chopped carbon fiber reinforced carbon foam composites", Materials Letters 63 (2009) 25-27.

[12] M.M. Shokrieh a, A. Saeedi a, M. Chitsazzadeh "Evaluating the effects of multi-walled carbon nanotubes on the mechanical properties of chopped strand mat/polyester composites", Materials and Design 56 (2014) 274-279
[13] Min-Seok Sohn \& Xiao-Zhi Hu "Processing of carbon-fiber/epoxy composites with cost-effective interlaminar reinforcement ",Composites Swnce and Technology 58 ( 1998) 211-220.

[14] Sua F, Zhang Z, Wang K, Jiang W, Liu W Tribological and mechanical properties of the composites made of carbon fabrics modified with various methods. Compos Part A 36 (2005) 1601-1607.

[15] Devendra K, Rangaswamy $\mathrm{T}$ Determination of mechanical properties of $\mathrm{Al}_{2} \mathrm{O}_{3}, \mathrm{Mg}(\mathrm{OH})_{2}$ and $\mathrm{SiC}$ filled E-glass/epoxy composites. Int J Eng Res Appl 2(5), (2012) 2028-2033

[16] Kaundal R, Patnaik A, Satapathy A Comparison of the mechanical and thermo-mechanical properties of unfilled and $\mathrm{SiC}$ filled short glass polyester composites. Silicon 4, (2012) 175-188

[17] Ward IM, Sweeney J (2004) An introduction to the mechanical properties of solid polymers. Wiley, New York

[18] Agarwal G, Patnaik A, Sharma RK Parametric optimization of three-body abrasive wear behavior of long and short carbon fibre reinforced epoxy composites. Tribology Material, surface and interfaces 7(3) (2013) 150-160

[19] Kumar S, Satapathy BK, Patnaik A Visco-elastic interpretations of erosion performance of short aramid fibre reinforced vinyl ester resin composites. J Mater Sci 46 ,(2011) 7489-7500. 